\title{
Research Progress on N-heterocyclic Carbene Boranes
}

\author{
Xue Wang, Yu-jie Yang, Yan-di Song, Shuang Zhao, Hong-jie Qu
}

College of Science, Heilongjiang Bayi Agricultural University, Daqing, 163319, Heilongjiang Province, P. R. China

DOI: $10.36348 /$ sijcms.2020.v03i10.002

| Received: 11.12.2020 | Accepted: 21.12.2020 | Published: 24.12.2020

*Corresponding author: Hong-jie Qu

\section{Abstract}

N-heterocyclic carbene boranes (NHC-boranes) are a new kind of compounds which have characteristic structures, luxuriant chemical properties, and preparation with a simple method. They can be widely utilized in various organic synthetic chemical reactions. As practical synthetic reagents or intermediates, it has now attracted attention. In order to show that the status of NHC-boranes in organic synthesis cannot be ignored, this article reviews the structural characteristics, preparation methods and typical chemical reactions of NHC-boranes. We hope that this review can attract more attention, promote the development of synthetic organic chemistry, and apply them to a wider range of areas.

Keywords: NHC-boranes, Preparation, Reaction.

Copyright $\odot 2020$ The Author(s): This is an open-access article distributed under the terms of the Creative Commons Attribution 4.0 International License (CC BY-NC 4.0) which permits unrestricted use, distribution, and reproduction in any medium for non-commercial use provided the original author and source are credited.

\section{INTRODUCTION}

N-Heterocyclic carbenes (NHCs) are a class of compounds with $\sigma$-type lone pair of electrons ${ }^{1}$. As a Lewis base, they can be stabilized by electron-deficient boranes to form a new type of complex called $\mathrm{N}$ Heterocyclic Carbene Boranes (NHC-boranes or NHC$\mathrm{BH}_{3}$ ). These compounds are similar in form to the complexes of Lewis acid and Lewis base, but in fact they have higher stability (higher than $\mathrm{R}_{3} \mathrm{~N} \cdot \mathrm{BH}_{3}$ and $\mathrm{R}_{3} \mathrm{P} \cdot \mathrm{BH}_{3}$ ). Their chemical reaction properties are also different from trivalent neutral boranes. They have their own unique chemical properties and can construct unusual new boron compounds and reaction intermediates.

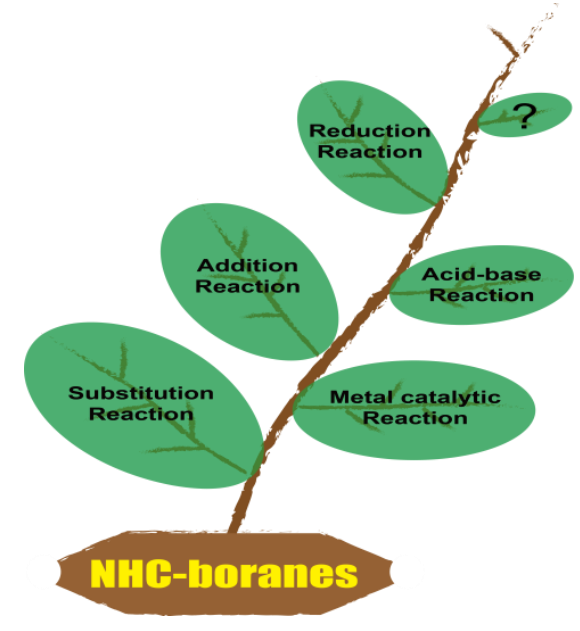

In recent years, several hot spots in the development of boron chemistry have focused on the construction of boron-boron multiple bonds [2-4], boron multi-center bonds [5] and NHC-boranes chemistry $[6,7]$.

Compounds with stable NHC-boranes structure take boron atom and its substituent as the reaction center, and it is easy to obtain many very stable synthetic intermediates. NHC-boranes did not show the typical chemical characteristics of borane, but proved their own rich chemical properties. As a low-cost stable white solid, NHC-boranes are easy to prepare, separate and handle; have good solubility in organic solvents and can be used as reagents or catalysts and coinitiators. Therefore, the position in organic chemical synthesis are becoming more and more prominent.

\section{Structure and preparation of NHC-boranes Structure of NHC-boranes}

Since Arduengo [8] reported stable Nheterocyclic carbene, the types of atoms or groups that form new compounds with these stable carbenes have gradually increased $[9,10]$. The carbene carbon atom is hybridized in the form of $\mathrm{sp} 2$, with a pair of electrons on the $\sigma$ orbital, generally in the form of singlet with only six electrons around it, which is an electrondeficient system. Considering the electronic effect, the lone pair of electrons on the p-orbitals of the two $\mathrm{N}$ atoms on the carbene ring and the empty p-orbitals on the carbene carbon atoms can form a conjugation effect, which can reduce the electron deficiency of the carbene carbon atoms. Considering the inductive effect, two 
nitrogen atoms with greater electronegativity are connected to the carbene carbon atom, and the lone pair of electrons on the carbene carbon atom can be stabilized due to the electron withdrawing effect of the nitrogen atom. In addition, if a $\mathrm{C}=\mathrm{C}$ double bond participates in the conjugation, the stability of the system can also be increased. Therefore, the $\mathrm{N}$ heterocyclic carbene formed by the imidazole ring is a relatively stable system. Figure 1 showed a typical structure of 1,3-dimethylimidazole-2-subunit (diMeImd; 1). Since this structure had a strong $\sigma$-donor and weak $\pi$-acceptor, it was considered to be a typical Lewis base. 2 is the simplest and typical NHC-boranes structure. They played an important role in transition metal chemistry [11, 12], ligands as catalysts [13, 14] and other reactions [15].

Few people pay attention to the coordination of $\mathrm{N}$-heterocyclic carbene with main group elements. This may be because it is inferred from the formal charge and nature of the hydrogen atom that 2 may itself undergo a hydroboration reaction. However, the structural analysis of 2 shows that the B atom in 2 is a four-valent atom with eight electrons, which is a stable compound and does not undergo 1,2-transition to generate boron hydride compounds. Therefore, NHCborane complexes have gradually gained attention in recent years [16, 17]. Figure-2 was a complex NHCborane 3 structure first described by Robinson [18] in 2007. The name of this type of substance is usually composed of three parts: $\mathrm{N}$-substituent abbreviations (such as dipp) are written in front, plus NHC ring abbreviations (such as Imd) and borane formula (such as $\mathrm{BH}_{3}$ ), so 3 can also be written as dipp-Imd- $\mathrm{BH}_{3}$.<smiles></smiles>

diMe-Imd: 1<smiles>[BH3-]C1N(C)C=CN1C</smiles>

diMe-Imd- $\mathrm{BH}_{3} 2$

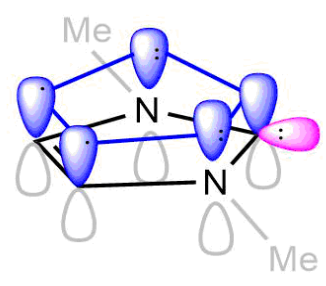

$\pi$ conjugation and $\sigma$ lone pair electrons in $\mathrm{NHC}$

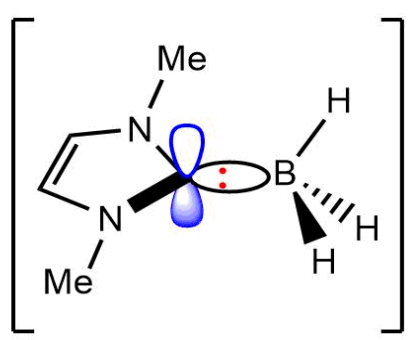

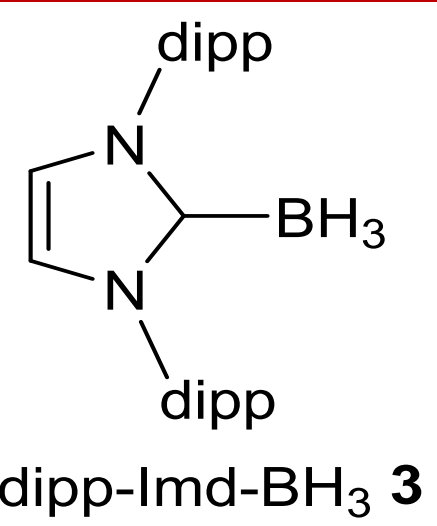

Fig-2: Structures of NHC-boranes 3

Ueng [19] used NHC-boranes for the radical chain reduction reaction of xanthate and related functional groups. In addition, based on the work of amine boranes [20] and phosphine boranes [21], DFT calculations showed that the B-H bond dissociation energy (BDE) of NHC-boranes 3 is $79 \sim 80 \mathrm{kcal} \cdot \mathrm{mol}^{-1}$ $[19,22]$, which was significantly lower than the bond dissociation energy of the $\mathrm{B}-\mathrm{H}$ bond in borane complexes of amines and phosphines ${ }^{23}$, so it had strong chemical activity.

\section{Preparation of NHC-boranes complex}

In 1993, Kuhn [24] used 1,3,4,5trimethylimidazole-2-subunit carbene 4 and $\mathrm{BH}_{3}-\mathrm{SMe}_{2}$ or $\mathrm{BF}_{3}-\mathrm{OEt}_{2}$ to form stable NHC-boranes, as shown in Scheme 1(a). In 2010, Bertrand group ${ }^{25}$ used cyclic (alkyl)-(amino) carbenes (CAAC) 6 instead of imidazole carbenes to react with Lewis acid $\mathrm{BH}_{3}$ to generate carbene borane 7, as shown in Scheme 1(b). In the same year, Bissinger [26] used carboxylic acid 9 to react with $\mathrm{BH}_{3}-\mathrm{SMe}_{2}$ using toluene as solvent and heated at $110^{\circ} \mathrm{C}$ to synthesize NHC-boranes 2 with a $64 \%$ yield, as shown in Scheme 1(c). In some preparation reactions, borohydride was used as a base to provide borane groups. Yamaguchi [27] made $\mathrm{NHC}^{-\mathrm{BEt}_{3}}$ complex by reacting imidazole salt with $\mathrm{LiBEt}_{3} \mathrm{H}$. Tang [28] used 1:10 equivalent of $\mathrm{LiBH}_{4}$ to produce 2 with a yield of $75 \%$.

After NHC-boranes has been widely concerned in organic synthesis reactions, the types of its preparation have also increased significantly in recent years [25, 29-34]. In the past few years, various NHC-boranes have been successfully prepared by selecting different NHC rings and substituents. The various structures are shown in Figure-3.

Fig-1: Structure and orbital diagram of NHC-boranes 1 and 2 
Xue Wang et al., Sch Int J Chem Mater Sci, Dec, 2020; 3(10): 152-163

(a)<smiles>CCOCCN(C)C1=C(C)N(C)C(C(=O)c2ccccc2)N1C</smiles>

$5 a \mathrm{R}=\mathrm{H}$

$\mathbf{5 b} \mathrm{R}=\mathrm{F}$

(b)<smiles>CC1(I)CC2(CCCC2)CN1Cc1ccccc1</smiles>

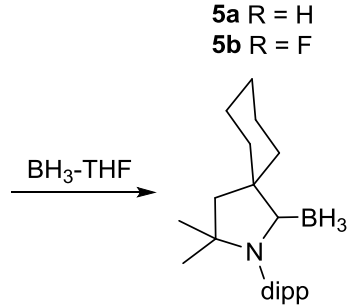

(c)

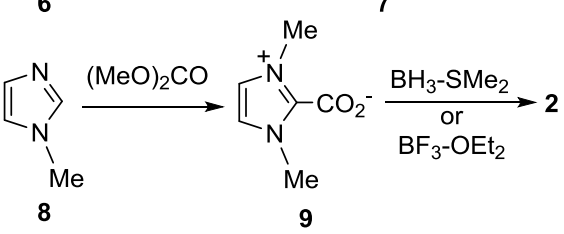

Scheme 1: Typical reaction for preparing NHC-boranes

\section{The reaction of $\mathrm{NHC}$-boranes in organic synthesis}

NHC-boranes take boron atom as the reactive center and has unique properties. They can be used as hydrogen donors to terminate free radical reactions [32], as reagents to participate in reduction reactions $[19,35]$, and occurred addition to unsaturated bonds [36-39], addition-elimination reactions [40-43] or substitution reaction $[44,45]$. They also can be used as substrates for boronation reactions to build new boron-containing chemical bonds [46-48], and used as catalysts and polymerization co-initiators [33, 49-52] to participate in chemical reactions. These organic reactions provide new methods and ideas for the synthesis of boroncontaining molecules and materials, the construction of boron-containing organic functional groups, and the development of boron chemistry.

They also provide valuable synthetic routes for the research of organic chemistry and expand the practicality of organic synthetic chemistry.

\section{Acid-Base Reaction}

NHC-boranes are weak bases similar to ammonia boranes and phosphine boranes. NHCboranes 3 does not react with acetic acid at room temperature or when heated to about $100^{\circ} \mathrm{C}$, so it appears to be a weaker base than borohydride. Therefore, NHC-boranes do not react with weak acids.

Solovyev [53] and Lindsay [30, 54] have reported that NHC-boranes only react with strong acids with $\mathrm{pKa}=1 \sim 2$. Scheme 2 showed an example of acid-base reaction between 3 and a typical strong acid. Such reaction was very important for the preparation of active NHC-boranes reagent. Most of the acid-base reactions in Scheme 2(a) produced monosubstituted products, with the exception of trifluoromethanesulfonic acid. The reaction between 3 and 2 equivalents of trifluoromethanesulfonic acid was very rapid, and the disubstituted product 11 was formed. A new onium ion was discovered in the study of the acid/base reaction of substituted NHC-boranes. It is known that treating NHC-boranes with 1 equivalent of trifluoromethanesulfonic acid or $\mathrm{HCl}$ will give monotrifluoroformate $\mathrm{NHC}_{-} \mathrm{BH}_{2}(\mathrm{OTf})$ or monochloride. The reaction with 2.5 equivalents of trifluoromethanesulfonic acid gives the ditrifluoromethane-sulfonate $\mathrm{NHC}-\mathrm{BH}(\mathrm{OTf})_{2}$. However, even at 5 equivalents, the tritrifluoromethanesulfonate $\mathrm{NHC}-\mathrm{B}(\mathrm{OTf})_{3}$ will not appear, but a substance containing a hydrogen bond structure is formed, as shown in Scheme 2(b) [55].

NHC-boranes reacted slowly with oxalic acid in acetonitrile at room temperature and rapidly forms NHC-borane oxalate at $80^{\circ} \mathrm{C}$. For example, in acetonitrile solvent, heated 2 and oxalic acid at $80^{\circ} \mathrm{C}$ for 2h. After two consecutive acid-base reactions, a new unknown heterocyclic NHC-boryl oxalate was obtained. A stable white solid 13 was isolated in a yield of 59\%, as shown in Scheme 3 [56].

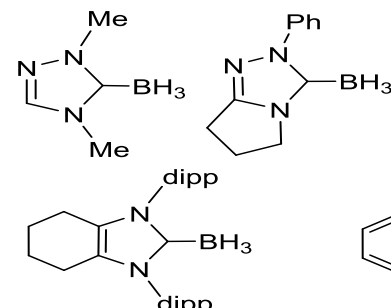<smiles></smiles><smiles>[B]C1N([In])c2ccccc2N1[In]</smiles><smiles>C=CC(=O)N1C=CN(c2c(C)cc(C)cc2C)C1Br</smiles><smiles>[B]C1N([GaH])C(C)(C)CC12CCCC2</smiles><smiles>[R]C1=C([R])N([R])C([Hg])N1[R]</smiles><smiles>[R3]C1N(C)c2ccccc2N1[13CH3]</smiles><smiles>[R7]C1=C([R])N(c2c([R8])cc([Z2])cc2[R8])C(C)N1c1c([R8])cc([Z2])cc1[R8]</smiles><smiles>[R]C1([R7])COC2=C3OCC([R7])([R7])N3C([B])N21</smiles>

$\mathrm{R}^{1}=\mathrm{H}, \mathrm{R}^{2}=\mathrm{Me} ; \mathrm{R}^{1}=\mathrm{H}, \mathrm{R}^{2}=$ dipp; $\mathrm{R}^{1}=\mathrm{H}, \mathrm{R}^{2}=$ cyclohexyl; $\mathrm{R}^{1}=\mathrm{H}, \mathrm{R}^{2}=i-\mathrm{Pr} ; \mathrm{R}^{1}=\mathrm{H}, \mathrm{R}^{2}=\mathrm{Ph}$ $\mathrm{R}^{1}=\mathrm{H}, \mathrm{R}^{2}=$ adamantyl;

$\mathrm{R}^{1}=\mathrm{Cl}, \mathrm{R}^{2}=\mathrm{Me} ; \mathrm{R}^{1}=\mathrm{CN}, \mathrm{R}^{2}=\mathrm{Me}$ $\mathrm{R}^{3}=\mathrm{CH}_{2} \mathrm{CH}=\mathrm{CH}_{2}$, Me;

$\mathrm{R}^{1}=\mathrm{R}^{5}=\mathrm{H}, \quad \mathrm{R}^{4}=\mathrm{Cl}$; $\mathrm{R}^{1}=\mathrm{H}, \quad \mathrm{R}^{4}=\boldsymbol{t}$-Bu, $\mathrm{R}^{5}=\mathrm{Me}$

$\mathrm{R}^{6}=\mathrm{R}^{7}=\mathrm{Me} ; \mathrm{R}^{6}=\mathrm{H}, \mathrm{R}^{7}=i-\mathrm{Pr}$

Fig-3: The species of the NHC-boranes 
Xue Wang et al., Sch Int J Chem Mater Sci, Dec, 2020; 3(10): 152-163

(a)

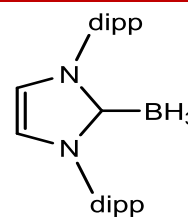

3

(b)<smiles>CCCCN1C=CN(C(C)C)C1CCC</smiles>

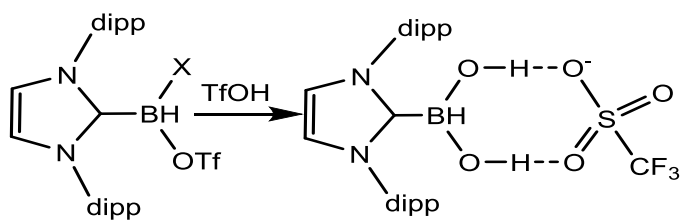

12

Scheme 2: NHC-boranes 3 representative acid-base reaction<smiles>[B]C1N(C)C=CN1C</smiles>

2<smiles>CN1C=CN(C)C1B1OC(=O)C(=O)O1</smiles>

13<smiles>O=C(O)C(=O)O</smiles>

Scheme 3: NHC-boranes 2 reaction with oxalic acid

\section{NHC-Boranes substitution reaction}

NHC-Boranes can also react with a variety of halogenating reagents, such as $\mathrm{N}$-bromosuccinimide (NBS), Niodosuccinimide (NIS), bromine and iodine, etc., as shown in Scheme 4 [53]. The resulting products were mono-, di- and tri-substituted. Among them, 3 iodination had higher selectivity. The reaction of 3 with only 0.5 equivalent of $\mathrm{I}_{2}$ gave a higher yield of $10 \mathrm{~b}$. It was speculated that the electrophilic substitution produced 0.5 equivalents of $10 \mathrm{~b}$ and $\mathrm{HI}$. The generated 0.5 equivalent of $\mathrm{HI}$ was then reacted with the remaining part of 3 through an acid-base reaction and converted into the target product $10 \mathrm{~b}$. The substitution reaction between 2 and $\mathrm{R}-\mathrm{Br}$ generates bromide $10 \mathrm{c}$ [57].

(a)

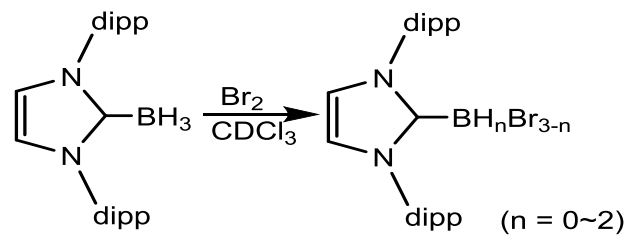

$10 \mathrm{c}, \mathrm{n}=2$

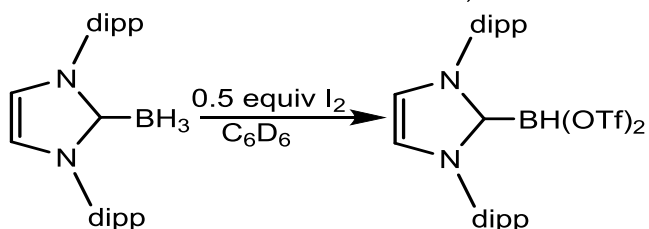

(b)

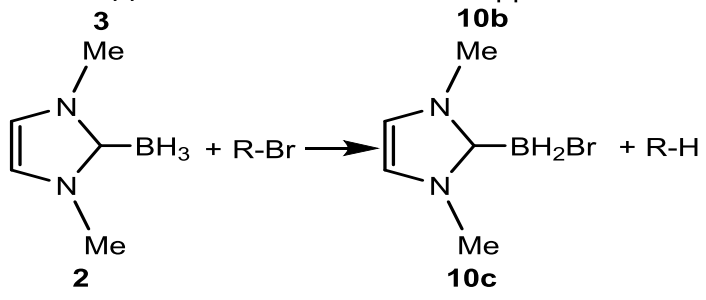

$\mathrm{R}=$ primary-alkyl, tert-alkyl, benzyl, allyl

Scheme 4: NHC-boranes 3 and 2 electrophilic halogenation reaction

Substituted NHC-boranes can also react with nucleophiles to undergo further substitution to generate a variety of NHC-borane derivatives. Substituted NHCboranes such as halogenated and sulfonate can undergo substitution reactions with nucleophiles to synthesize a variety of NHC boron-containing halides, cyanides and sulfur derivatives, as shown in Scheme 5(a). The boron compound 14 is isocyanide, isocyanate and nitro compounds. These rare new members have stable chromatography and have important research value in organic synthesis. Robinson [18] reported a neutral and stable NHC-boranes containing $\mathrm{B}=\mathrm{B}$, which attracted considerable attention. Pan [58] reacted the treated diMe-Imd- $\mathrm{BBr}_{3}$ complex 15 with potassium graphite $\left(\mathrm{KC}_{8}\right)$ to obtain borane 16 and $\mathrm{B}=\mathrm{B}$ product 17 . Mixture 17 was a secondary product, but it was also stable, and can be separated from 16 with a separation yield of $12 \%$, as shown in Scheme 5(b). The substituted NHCboranes can also be used as a source of other types of neutral nucleophiles to prepare thioethers and thioesters. $\mathrm{NHC}_{-} \mathrm{BH}_{3-\mathrm{n}} \mathrm{Y}_{\mathrm{n}}$ ( $\mathrm{Y}$ is a potential nucleophile), such as $\mathrm{NHC}-\mathrm{BH}(\mathrm{SPh})_{2} 18$ can also provide -SPh to prepare thioether 19, as shown in Scheme 5(c).

The reaction of NHC-boranes 2 and diaryl or diisoaryl disulfides resulted in diMe-Imd- $\mathrm{BH}_{2} \mathrm{SAr} 20$ and diMe-Imd-BH(SAr $)_{2}$ 21. One equivalent of disulfide protected from light was conducive to the formation of NHC-boron-based monosulfide 20, and 2 equivalents of disulfide illuminated by light was conducive to the formation of NHC-boron-based disulfide 21. Most of these substitution reactions were thought to proceed through free radical chains, in which 
Xue Wang et al., Sch Int J Chem Mater Sci, Dec, 2020; 3(10): 152-163

S-S bond breaking and substitution by NHC-boron was a key step, as shown in Scheme 6 [59].

(a)

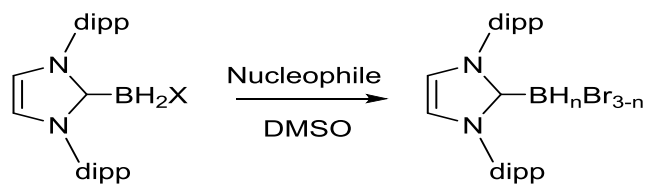

14

10a, $X=$ OTf $\quad \mathrm{Nu}=\mathrm{N}_{3}, \mathrm{NC}, \mathrm{CN}, \mathrm{NCO}$,

$10 b, X=O T$

(b)<smiles>O=C(Br)N1C=CN(Cl)C1Br</smiles>

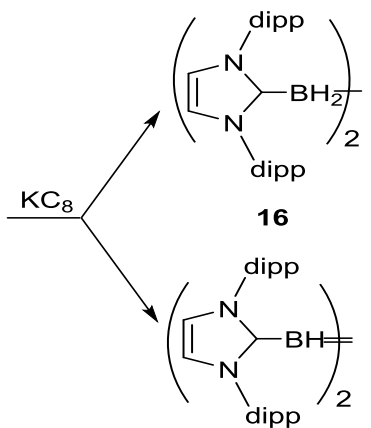

(c)<smiles>BC1N(C)C=CN1C</smiles>

17

$\mathrm{PhCH}_{2} \mathrm{Br}$

$\mathrm{PhCH}_{2} \mathrm{SPh}$

19

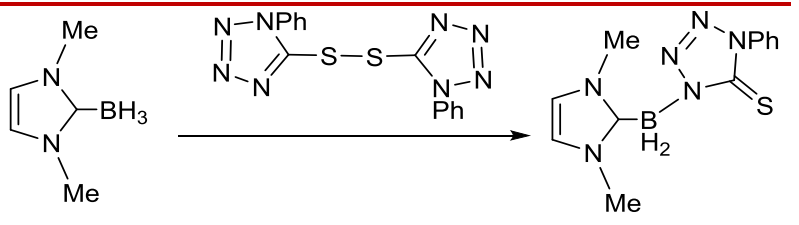

2

ArSSAr<smiles>BC1N(C)C=CN1C</smiles>

21

Scheme 6: NHC-boranes 2 and disulfide substitution reaction

NHC-boranes reacted with 5-diazo-2,2dimethyl-1,3-dioxane-4,6-dione 22 in dichloromethane at $40^{\circ} \mathrm{C}$. The $\mathrm{NHC}$-borohydrazone derivative 23 of 2,2 dimethyl-1,3-dioxane-4,6-dione was obtained. Dihydrazone 24 was generated when treated with $\mathrm{I}_{2}$ at room temperature in dichloromethane. Both monohydrazone and dihydrazone were yellow solids that were stable to chromatography and storage, as shown in Scheme 7 [60].

Scheme 5: Substituted NHC-boranes substitution reaction

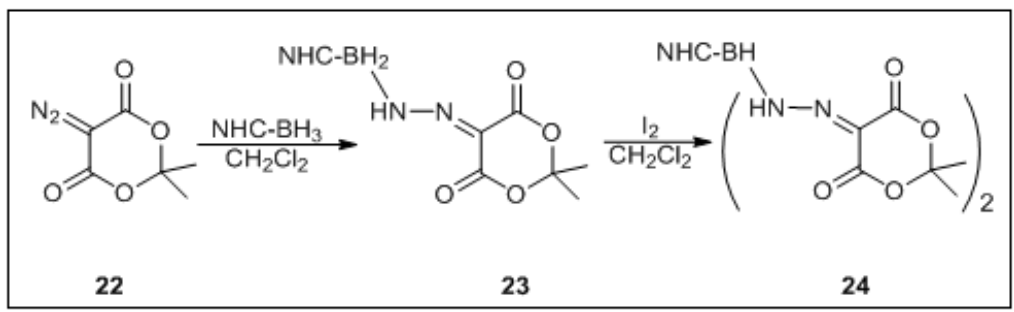

Scheme 7: Substitution reaction of NHC-boranes and diazodione

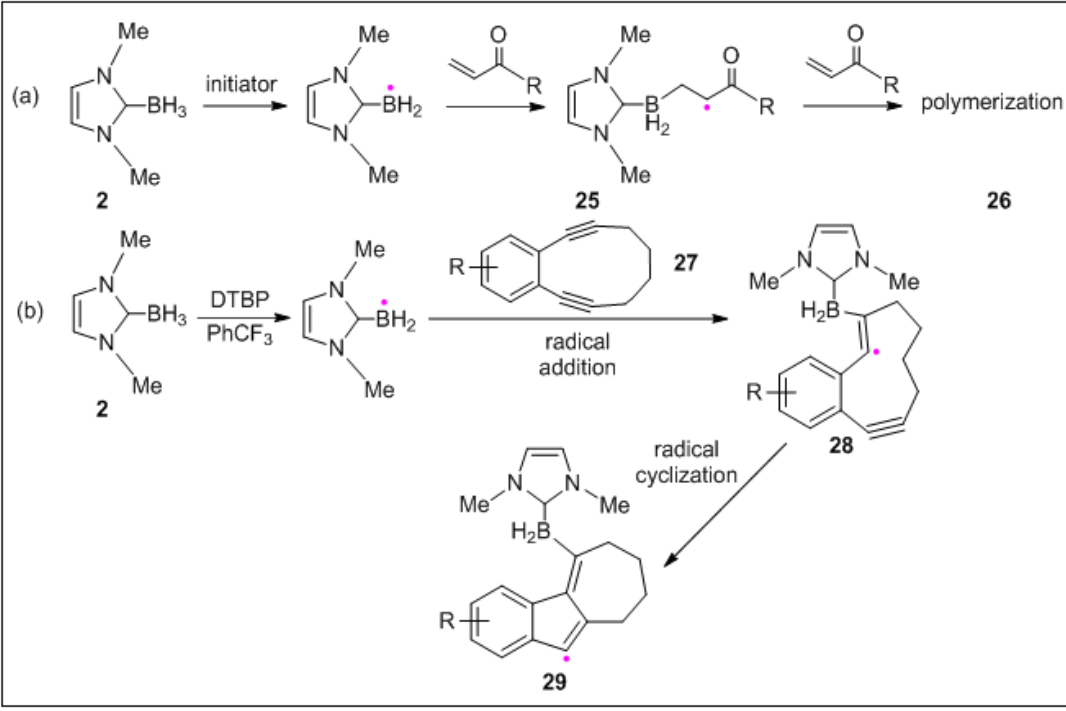

Scheme 8: NHC-boranes 2 addition reaction 
(a)<smiles>COCC(=CC(=O)OC)C(=O)OC</smiles><smiles></smiles>

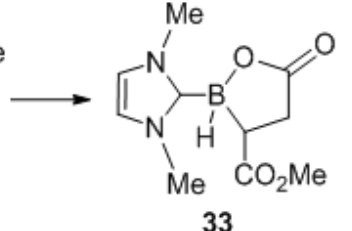

(b)

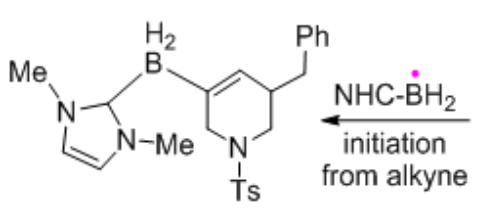

35<smiles>[R]OC1C(C([R])=O)[C@H]1C1N(C)C=CN1C</smiles>

37<smiles>CN(C)C/C=C/Pc1ccccc1</smiles>
34<smiles>C=C1CN([13F])C[C@H](BC2N(C)C=CN2C)[C@@H]1c1ccccc1</smiles>

36

(c)

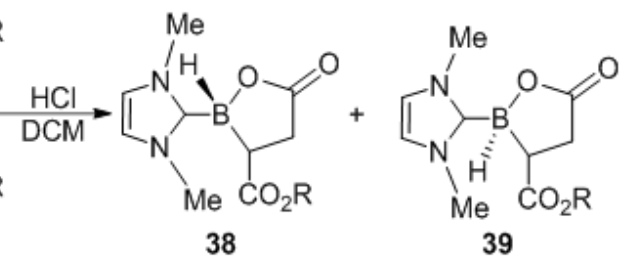

Scheme 9: The addition reaction of substituted NHC-boranes

\section{NHC-boranes addition reaction}

NHC-boranes can also react with some unsaturated substances. For example, the free radical initiator initiated NHC-boranes 2 to generate NHCboron radicals, and then reacted with ketene or cycloalkynes to generate carbon radical intermediates 25 or 28 . Then, the addition reaction of free radicals continued to generate polymer 26 or cyclic compound 29, as shown in Scheme 8 [61].

NHC-boranes 30 containing ester substituents was initiated by DTBP to generate the NHC-borane intermediate 31. 31 Boron radicals underwent intramolecular 5-endo addition reaction to generate five-membered boron heterocyclic ring 32 . Then 32 removed the alkyl radicals to generate the fivemembered ring lactone 33 [62, 63]. NHC-boranes and 1,6-enyne substance 34 were added at different positions to generate six-membered azaheterocyclic ring 35 and six-membered azaheterocyclic ring $36^{64}$, such as Scheme 9(a), (b). Wen [65] studied the ringopening addition of NHC-boranes 37 with ester substituents in the presence of $\mathrm{HCl}$ to generate stable $\gamma$ NHC-boron- $\gamma$-lactone 38 and 39, with a separation yield ranging from $40 \%$ to $73 \%$, as shown in Scheme 9(c).

NHC- $\mathrm{BH}_{2} \cdot$ was a new type of boron-centered radical. A large number of experiments had obtained the Barton-McCombie chain reaction mechanism [32], as shown in Scheme 10. For example, when various xanthogenates 40 reacted with $\mathrm{NHC}$-boranes, they were first initiated by $\mathrm{AIBN}$ at $80^{\circ} \mathrm{C}$ or triethylborane at room temperature to generate $\mathrm{NHC}-\mathrm{BH}_{2}$. free radical. $\mathrm{NHC}-\mathrm{BH}_{2}$. free radical was then added to the $\mathrm{C}=\mathrm{S}$ double bond in the xanthate to generate a carbon radical intermediate 41. $\mathrm{C}-\mathrm{O}$ bond in 41 was broken, generating 42 free radical and NHC-substituted borane 43. NHC-boranes can continue to supply 42 hydrogen to generate 44 hydrogen migration reduction products.

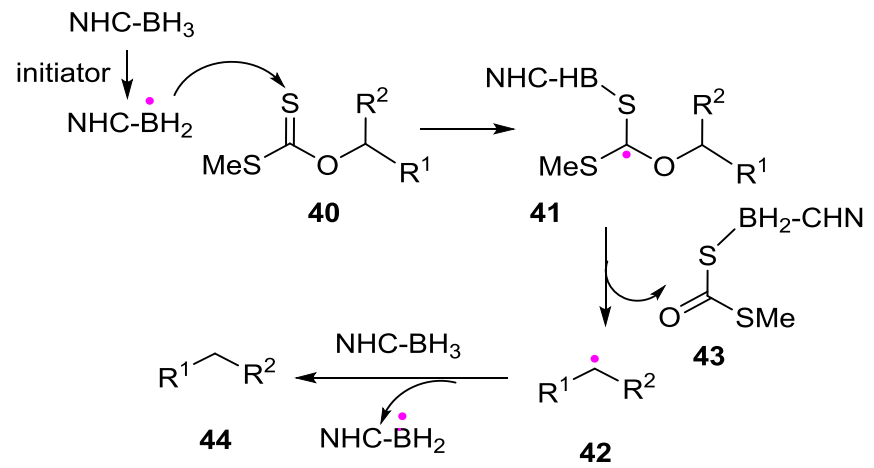

Scheme 10: NHC-boranes free radical Barton-McCombie mechanism 


\section{Metal catalytic reaction}

Aryl halides, alkenyl halides and triflate cannot be directly reduced by NHC-boranes, but these reductions can be promoted by various palladium catalysts. For example, 4-iodoacetophenone 45 and NHC-boranes 46 added palladium acetate and 1,1'bis(diphenylphosphine) ferrocene to tetrahydrofuran, and heated to obtain acetophenone 47. The product detected by GC was unique ${ }^{33}$, as shown in Scheme 11(a), (b). Therefore, aryl iodide and aryl triflate can be reduced by NHC-boranes when catalyzed by palladium.
Thomas [66] studied a series of neutral ligandborane complexes ${\mathrm{L}-\mathrm{BH}_{3}}_{3}$ ( $\mathrm{L}$ is NHC, amine, pyridine or phosphine), and the relative reactivity of cyanoborohydride anion and methyl 2phenyldiazoacetate 51 in the reaction catalyzed by $\mathrm{Rh}(\mathrm{II})$. Separation of ester products by stable $\alpha$-boryl flash chromatography showed that the reactivity of borane with NHC as the ligand was relatively high, second only to pyr- $\mathrm{BH}_{3}$, as shown in Scheme 11(c). (a)<smiles>CC(=O)c1ccc(I)cc1</smiles><smiles>[B]C1N2CCCC2=NN1c1ccccc1</smiles>

46

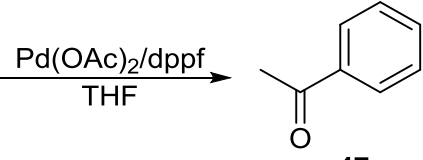

(b)<smiles>O=C(OC1CCCCC1)c1ccc(O)cc1</smiles>

48<smiles></smiles><smiles>[Te]</smiles>

(c)<smiles>COC(=O)C(=[W])c1ccccc1</smiles>

51

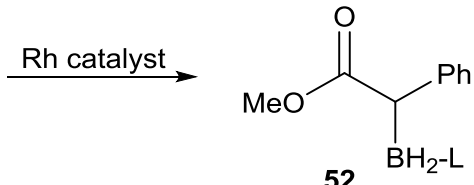

pyr- $\mathrm{BH}_{3}>\mathrm{NHC}-\mathrm{BH}_{3}>\mathrm{Me}_{3} \mathrm{~N}-\mathrm{BH}_{3}>\mathrm{BH}_{3} \mathrm{CN}>\mathrm{Ph}_{3} \mathrm{P}-\mathrm{BH}_{3}$ " $\mathrm{Bu}_{3} \mathrm{P}-\mathrm{BH}_{3}$

Scheme 11: NHC-boranes metal catalyzed reaction

\section{Reduction reaction}

From another point of view, the aforementioned substitution reaction and metalcatalyzed reaction also show the performance of NHCboranes to donate hydrogen to reduce halogenated compounds. Under silica gel conditions, aldehydes and ketones were selectively reduced to primary and secondary alcohols by NHC-boranes 2, and the yield was high. This reaction process was worthy of attention, because all materials were stable, easy to handle, and the method was gentle, did not require quenching, and the reaction and separation processes were very convenient, as shown in Scheme 12 [52].

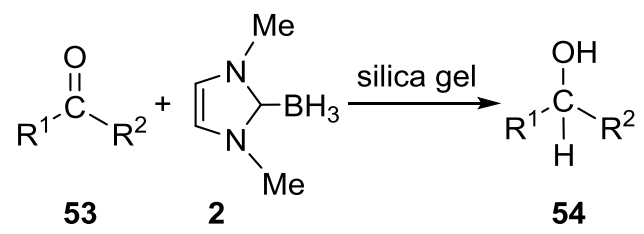

Scheme 12: Silica-catalyzed NHC-boranes 2 reduction of aldehydes and ketones

NHC-boranes can assist in the reduction of R$\mathrm{X}$ to $\mathrm{R}-\mathrm{H}$ with a radical chain reaction as a mechanism, and the reaction with xanthate was particularly typical. Scheme 1-13 listed a series of NHC-boranes reduction reactions of xanthate [37, 42, 67].

\section{Scheme 13: A series of NHC-boranes reduction reactions of xanthate}

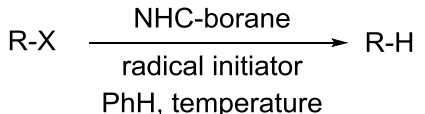


Xue Wang et al., Sch Int J Chem Mater Sci, Dec, 2020; 3(10): 152-163

\begin{tabular}{|c|c|c|c|c|c|c|}
\hline $\bar{X}=$ & $\mathbf{R}=$ & NHC-borane & $\begin{array}{l}\text { radical initiator } \\
\text { (equiv.) }\end{array}$ & temperature & Yield (\%) & ref. \\
\hline \multirow{8}{*}{$\mathrm{OC}(=\mathrm{S}) \mathrm{SMe}$} & \multirow{2}{*}{$\mathrm{BnO}^{+}$spr $_{\text {st }} \mathrm{Et}$} & 3 & $\operatorname{AlBN}(2.0)$ & $80^{\circ} \mathrm{C}$ & 65 & 37 \\
\hline & & 44 & AlBN (0.5) & $80^{\circ} \mathrm{C}$ & 70 & 37 \\
\hline & \multirow{3}{*}{$\mathrm{BnO}_{5} \mathrm{~N}^{i} \mathrm{Pr}$} & 3 & AlBN (2.0) & $80^{\circ} \mathrm{C}$ & 64 & 37 \\
\hline & & 44 & AlBN (0.5) & $80^{\circ} \mathrm{C}$ & 63 & 37 \\
\hline & & 44 & AlBN (0.2) & $80^{\circ} \mathrm{C}$ & 67 & 37 \\
\hline & & 44 & AlBN (0.5) & $80^{\circ} \mathrm{C}$ & $\begin{array}{l}\mathrm{BnO} / \mathrm{Et} \\
57\end{array}$ & 37 \\
\hline & $\mathrm{BnC}$ & 44 & AlBN (0.5) & $80^{\circ} \mathrm{C}$ & $\begin{array}{l}\mathrm{BnO}^{-} \\
67\end{array}$ & 37 \\
\hline & & 44 & AlBN (0.5) & $80^{\circ} \mathrm{C}$ & 61 & 37 \\
\hline \multirow[t]{3}{*}{ I } & & 2 & $\mathrm{Et}_{3} \mathrm{~B}(1.0)$ & r.t. & 77 & 67 \\
\hline & & 3 & $\mathrm{Et}_{3} \mathrm{~B}(1.0)$ & r.t. & 35 & 67 \\
\hline & & 2 & AlBN (1.0) & $80^{\circ} \mathrm{C}$ & 63 & 67 \\
\hline \multirow{3}{*}{$\mathrm{Br}$} & & 2 & $\mathrm{Et}_{3} \mathrm{~B}(1.0)$ & r.t. & 79 & 67 \\
\hline & & 2 & AlBN (1.0) & $80^{\circ} \mathrm{C}$ & 77 & 67 \\
\hline & & 2 & DTBP (1.0) & $60^{\circ} \mathrm{C}$ & 73 & 67 \\
\hline
\end{tabular}

\section{CONCLUSIONS AND PERSPECTIVE}

Before 2008, NHC-boranes may be considered a rare compound. Due to the increasing attention in recent years, the research has progressed rapidly. The formation of NHC-boranes strengthened the borane family. Because the properties of NHC-boranes are very different from amine borane and phosphine borane, it greatly enriches the applications of borane in organic chemistry. Most of NHC-boranes are easy to synthesize and characterize, and many structures are stable in air and water which can be purified by simple chromatography. The production of new NHC-boron free radical active intermediates (boron free radicals, cationic free radicals and anionic free radicals) make NHC-boranes promising to become important organic synthesis reagents, catalysts and co-initiators. NHCboranes will have more vitality and comprehensive potential in organic synthesis.
This work was supported by National University Student Innovation and Entrepreneurship Project (No.201810223016) of China.

NOTE: The diagram is acceptable in a colored form. Publication of the colored G.A. is free of charge.

For publication, electronic data of the colored G.A. should be submitted. Preferred data format is EPS, PS, CDX, PPT, and TIFF.

If the data of your G.A. is "bit-mapped image" data (not "vector data"), note that its print-resolution should be 300 dpi.

You are requested to put a brief abstract (50-60words, one paragraph style) with the graphical abstract you provided, so that readers can easily understand what the graphic shows. 


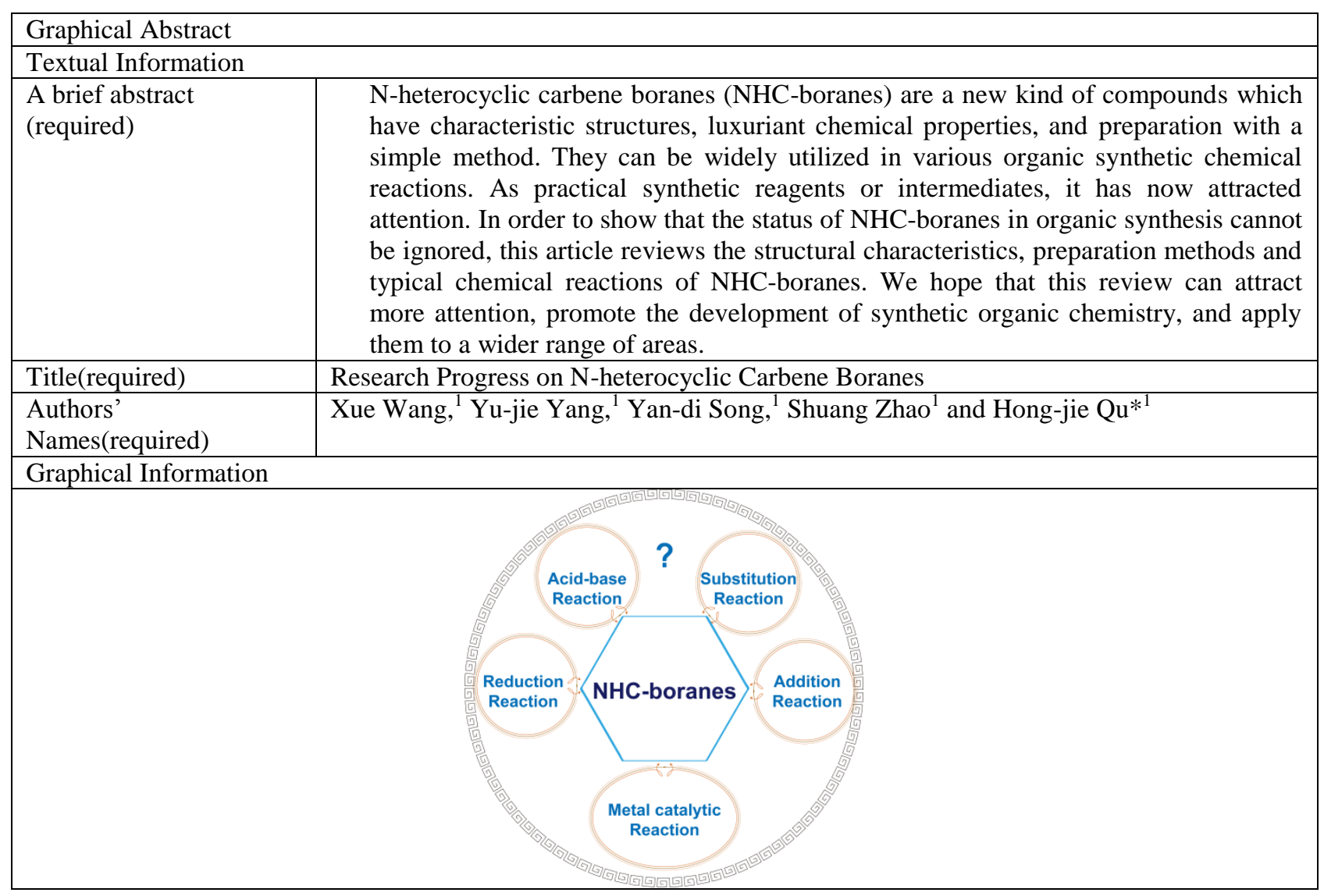

\section{REFERENCES}

1. Doddi, A., Peters, M., \& Tamm, M. (2019). NHeterocyclic Carbene Adducts of Main Group Elements and Their Use as Ligands in Transition Metal Chemistry. Chemical reviews, 119(12), 6994-7112.

2. Braunschweig, H., Dewhurst, R. D., Hammond, K., Mies, J., Radacki, K., \& Vargas, A. (2012). Ambient-temperature isolation of a compound with a boron-boron triple bond. Science, 336(6087), 1420-1422.

3. Braunschweig, H., \& Dewhurst, R. D. (2013). Single, Double, Triple Bonds and Chains: The Formation of Electron- Precise B $\square \quad$ B Bonds. Angewandte Chemie International Edition, 52(13), 3574-3583.

4. Zhang, X., Wu, T., Wang, H., Zhao, R., Chen, H., Wang, T., ... \& Sun, X. (2019). Boron nanosheet: an elemental two-dimensional (2D) material for ambient electrocatalytic N2-to-NH3 fixation in neutral media. Acs Catalysis, 9(5), 4609-4615.

5. Sergeeva, A. P., Popov, I. A., Piazza, Z. A., Li, W. L., Romanescu, C., Wang, L. S., \& Boldyrev, A. I. (2014). Understanding boron through size-selected clusters: structure, chemical bonding, and fluxionality. Accounts of chemical research, 47(4), 1349-1358.

6. Staubitz, A., Robertson, A. P., Sloan, M. E., \& Manners, I. (2010). Amine- and phosphineborane adducts: new interest in old molecules. Chemical reviews, 110(7), 4023-4078.
7. Taniguchi, N., \& Kitayama, K. (2019). Dihydrosulfenylation of Alkynes with Thiols Using a Nickel Catalyst Through a Radical Process. Asian Journal of Organic Chemistry, 8(8), 1468-1471.

8. Arduengo III, A. J., Harlow, R. L., \& Kline, M. (1991). A stable crystalline carbene. Journal of the American Chemical Society, 113(1), 361-363.

9. Kühl, O. (2007). The chemistry of functionalised N-heterocyclic carbenes. Chemical Society Reviews, 36(4), 592-607.

10. Arduengo, A. J., \& Bertrand, G. (2009). Carbenes introduction. Chem Rev. 109, 3209.

11. Bellemin-Laponnaz, S., Despagnet-Ayoub, E., Díez-González, S., Gade, L. H., Glorius, F., Louie, J., ... \& Stahl, S. S. (2004). N-heterocyclic carbenes in transition metal catalysis. Top. Organomet. Chem, 21.

12. Diez-Gonzalez, S., Marion, N., \& Nolan, S. P. (2009). N-heterocyclic carbenes in late transition metal catalysis. Chemical Reviews, 109(8), 36123676.

13. Enders, D., Niemeier, O., \& Henseler, A. (2007). Organocatalysis by N-heterocyclic carbenes. Chemical Reviews, 107(12), 5606-5655.

14. Marion, N., Díez- González, S., \& Nolan, S. P. (2007). N-heterocyclic carbenes as organocatalysts. Angewandte Chemie International Edition, 46(17), 2988-3000.

15. Dröge, T., \& Glorius, F. (2010). The Measure of All Rings- N- Heterocyclic 
Carbenes. Angewandte Chemie International Edition, 49(39), 6940-6952.

16. Kirmse, W. (2005). Carbene complexes of nonmetals. European journal of organic chemistry, 2005(2), 237-260.

17. Kuhn, N., \& Al-Sheikh, A. (2005). 2, 3Dihydroimidazol-2-ylidenes and their main group element chemistry. Coordination chemistry reviews, 249(7-8), 829-857.

18. Wang, Y., Quillian, B., Wei, P., Wannere, C. S., Xie, Y., King, R. B., \& Schaefer III, H. F. (2007). von R. Schleyer, P.; Robinson, GH. J. Am. Chem. Soc, 129, 12412-12413.

19. Ueng, S. H., Makhlouf Brahmi, M., Derat, E., Fensterbank, L., Lacote, E., Malacria, M., \& Curran, D. P. (2008). Complexes of borane and Nheterocyclic carbenes: a new class of radical hydrogen atom donor. Journal of the American Chemical Society, 130(31), 10082-10083.

20. Roberts, B. (1999). Polarity-reversal catalysis of hydrogen-atom abstraction reactions: concepts and applications in organic chemistry. Chemical Society Reviews, 28(1), 25-35.

21. Barton, D. H., \& Jacob, M. (1998). Phosphineboranes as selective reagents for the radical deoxygenation of a hindered secondary alcohol. Tetrahedron letters, 39(11), 1331-1334.

22. Hioe, J., Karton, A., Martin, J. M., \& Zipse, H. (2010). Borane-Lewis Base Complexes as Homolytic Hydrogen Atom Donors. Chemistry-A European Journal, 16(23), 6861-6865.

23. Rablen, P. R. (1997). Large effect on borane bond dissociation energies resulting from coordination by Lewis bases. Journal of the American Chemical Society, 119(35), 8350-8360.

24. Kuhn, N., Henkel, G., Kratz, T., Kreutzberg, J., Boese, R., \& Maulitz, A. H. (1993). Derivate des Imidazols, VI. Stabile Carben- Borane. Chemische Berichte, 126(9), 2041-2045.

25. Frey, G. D., Masuda, J. D., Donnadieu, B., \& Bertrand, G. (2010). Activation of Si $\square$ H, B $\square$ H, and $\mathrm{P} \square \mathrm{H}$ Bonds at a Single Nonmetal Center. Angewandte Chemie, 122(49), 9634-9637.

26. Bissinger, P., Braunschweig, H., Kupfer, T., \& Radacki, K. (2010). Monoborane NHC adducts in the coordination sphere of transition metals. Organometallics, 29(17), 3987-3990.

27. Yamaguchi, Y., Kashiwabara, T., Ogata, K., Miura, Y., Nakamura, Y., Kobayashi, K., \& Ito, T. (2004). Synthesis and reactivity of triethylborane adduct of N-heterocyclic carbene: versatile synthons for synthesis of N-heterocyclic carbene complexes. Chemical communications, (19), 21602161.

28. Tang, C. Y., Smith, W., Thompson, A. L., Vidovic, D., \& Aldridge, S. (2011). Iridium- Mediated Borylation of Benzylic $\mathrm{C} \square \mathrm{H}$ Bonds by Borohydride. Angewandte Chemie, 123(6), 13951398.
29. Fensterbank, L. (2010). Lac ${ }^{\wedge}$ ote, E.; Malacria, M.; Curran, DP. Org. Lett, 12, 3002-3005.

30. Lindsay, D. M., \& McArthur, D. (2010). The synthesis of chiral N-heterocyclic carbene-borane and-diorganoborane complexes and their use in the asymmetric reduction of ketones. Chemical communications, 46(14), 2474-2476.

31. Walton, J. C. (2009). Linking Borane with NHeterocyclic Carbenes: Effective HydrogenAtom Donors for Radical Reactions. Angewandte Chemie International Edition, 48(10), 1726-1728.

32. Ueng, S. H., Solovyev, A., Yuan, X., Geib, S. J., Fensterbank, L., Lacôte, E., ... \& Curran, D. P. (2009). N-Heterocyclic carbene boryl radicals: a new class of boron-centered radical. Journal of the American Chemical Society,131(31), 1125611262.

33. Chu, Q., Makhlouf Brahmi, M., Solovyev, A., Ueng, S. H., Curran, D. P., Malacria, M., ... \& Lacôte, E. (2009). Ionic and Organometallic Reductions with N-Heterocyclic Carbene Boranes. Chemistry-A European Journal, 15(47), 12937-12940.

34. Ono, S., Watanabe, T., Nakamura, Y., Sato, H., Hashimoto, T., \& Yamaguchi, Y. (2017). Synthesis of $\mathrm{N}$-heterocyclic carbene boranes via silver N-heterocyclic carbene complexes. Polyhedron, 137, 296-305.

35. Ueng, S. H., Fensterbank, L., Lacôte, E., Malacria, M., \& Curran, D. P. (2011). Radical reductions of alkyl halides bearing electron withdrawing groups with N-heterocyclic carbene boranes. Organic \& biomolecular chemistry, 9(9), 3415-3420.

36. Dai, W., Geib, S. J., \& Curran, D. P. (2019). Facile Synthesis of $\alpha$-N-Heterocyclic Carbene-Boryl Ketones from N-Heterocyclic Carbene-Boranes and Alkenyl Triflates. Journal of the American Chemical Society, 141(31), 12355-12361.

37. Shimoi, M., Maeda, K., Geib, S. J., Curran, D. P., \& Taniguchi, T. (2019). Esters as Radical Acceptors: $\quad \beta$ - NHC- Borylalkenyl Radicals Induce Lactonization by $\mathrm{C}^{-} \mathrm{C}$ Bond Formation/Cleavage on Esters. Angewandte Chemie International Edition, 58(19), 6357-6361.

38. Dai, W., Geib, S. J., \& Curran, D. P. (2020). 1, 4Hydroboration reactions of electron-poor aromatic rings by $\mathrm{N}$-heterocyclic carbene boranes. Journal of the American Chemical Society, 142(13), 62616267.

39. Zhu, C., Dong, J., Liu, X., Gao, L., Zhao, Y., Xie, J., ... \& Zhu, C. (2020). Photoredox- Controlled $\beta$ - Regioselective Radical Hydroboration of Activated Alkenes with NHCBoranes. Angewandte Chemie. 59, 12817.

40. Bolt, D. A., \& Curran, D. P. J. (2017) Org Chem. 82(24), 13746.

41. Jin, J. K., Zhang, F. L., Zhao, Q., Lu, J. A., \& Wang, Y. F. (2018). Synthesis of diverse boronhandled $\mathrm{N}$-heterocycles via radical borylative 
cyclization of N-allylcyanamides. Organic letters, 20(23), 7558-7562.

42. Kawamoto, T., Geib, S. J., \& Curran, D. P. (2015). Radical reactions of N-heterocyclic carbene boranes with organic nitriles: cyanation of NHCboranes and reductive decyanation of malononitriles. Journal of the American Chemical Society, 137(26), 8617-8622.

43. Kawamoto, T., Oritani, K., Kawabata, A., Morioka, T., Matsubara, H., \& Kamimura, A. (2020). Hydrodecyanation of Secondary Alkyl Nitriles and Malononitriles to Alkanes using DiMeImdBH3. The Journal of Organic Chemistry, 85(9), 6137-6142.

44. Takahashi, K., Shimoi, M., Watanabe, T., Maeda, K., Geib, S. J., Curran, D. P., \& Taniguchi, T. (2020). Revisiting Polyfluoroarenes as Radical Acceptors: Radical C-F Bond Borylation of Polyfluoroarenes with N-Heterocyclic Carbene Boranes and Synthesis of Borane-Containing Liquid Crystals. Organic Letters, 22(5), 20542059.

45. Xia, P. J., Ye, Z. P., Hu, Y. Z., Xiao, J. A., Chen, K., Xiang, H. Y., ... \& Yang, H. (2020). Photocatalytic C-F Bond Borylation of Polyfluoroarenes with NHC-boranes. Organic Letters, 22(5), 1742-1747.

46. Huang, X., Garcia-Borràs, M., Miao, K., Kan, S. J., Zutshi, A., Houk, K. N., \& Arnold, F. H. (2019). A biocatalytic platform for synthesis of chiral $\alpha$ trifluoromethylated organoborons. ACS central science, 5(2), 270-276.

47. Allen, T. H., Geib, S. J., \& Curran, D. P. (2016). Radical and Thermal Reactions of N-Heterocyclic Carbene Boranes with Diazo Compounds. Organometallics, 35(17), 2975-2979.

48. Walton, J. C., Dai, W., \& Curran, D. P. (2020). EPR Studies on the Addition of Ligated Boryl Radicals to Carbonyl Compounds. The Journal of Organic Chemistry, 85(6), 4248-4255.

49. Telitel, S., Vallet, A. L., Schweizer, S., Delpech, B., Blanchard, N., Morlet-Savary, F., ... \& Lalevée, J. (2013). Formation of N-heterocyclic carbene-boryl radicals through electrochemical and photochemical cleavage of the $\mathrm{B}-\mathrm{S}$ bond in $\mathrm{N}$ heterocyclic carbene-boryl sulfides. Journal of the American Chemical Society, 135(45), 1693816947.

50. Lacôte, E., Curran, D. P., \& Lalevée, J. (2012). NHC-boranes: air-and water-tolerant co-initiators for type II photopolymerizations. Chimia, 66(6), 382-385.

51. Wang, M. H., \& Chen, L. Y. (2017). An efficient $\mathrm{FeCl} 3$-mediated approach for reduction of ketones through N-heterocyclic carbene boranes. Tetrahedron Letters, 58(8), 732-735.

52. Taniguchi, T., \& Curran, D. P. (2012). Silica gel promotes reductions of aldehydes and ketones by N-heterocyclic carbene boranes. Organic letters, 14(17), 4540-4543.
53. Solovyev, A., Chu, Q., Geib, S. J., Fensterbank, L., Malacria, M., Lacôte, E., \& Curran, D. P. (2010). Substitution Reactions at Tetracoordinate Boron: Synthesis of N-Heterocyclic Carbene Boranes with Boron- Heteroatom Bonds. Journal of the American Chemical Society, 132(42), 1507215080.

54. McArthur, D., Butts, C. P., \& Lindsay, D. M. (2011). A dialkylborenium ion via reaction of $\mathrm{N}$ heterocyclic carbene-organoboranes with Brønsted acids - synthesis and DOSY NMR studies. Chemical communications, 47(23), 66506652.

55. Solovyev, A., Geib, S. J., Lacôte, E., \& Curran, D. P. (2012). Reactions of boron-substituted Nheterocyclic carbene boranes with triflic acid. Isolation of a new dihydroxyborenium cation. Organometallics, 31(1), 54-56.

56. Bolt, D. A., Geib, S. J., \& Curran, D. P. (2018). Synthesis and characterization of N-heterocyclic carbene complexes of 1, 3, 2-dioxaborolane-4, 5dione (NHC-boryl oxalates). Tetrahedron, 74(49), 6961-6965.

57. Walton, J. C., Brahmi, M. M., Fensterbank, L., Lacôte, E., Malacria, M., Chu, Q., ... \& Curran, D. P. (2010). EPR studies of the generation, structure, and reactivity of $\mathrm{N}$-heterocyclic carbene borane radicals. Journal of the American Chemical Society, 132(7), 2350-2358.

58. Pan, X., \& Curran, D. P. (2014). Neutral Sulfur Nucleophiles: Synthesis of Thioethers and Thioesters by Substitution Reactions of NHeterocyclic Carbene Boryl Sulfides and Thioamides. Organic letters, 16(10), 2728-2731.

59. Pan, X., Vallet, A. L., Schweizer, S., Dahbi, K., Delpech, B., Blanchard, N., ... \& Lacôte, E. (2013). Mechanistic and preparative studies of radical chain homolytic substitution reactions of $\mathrm{N}$-heterocyclic carbene boranes and disulfides. Journal of the American Chemical Society, 135(28), 10484-10491.

60. Dai, W., Geib, S. J., \& Curran, D. P. (2018). Reactions of N-Heterocyclic Carbene Boranes with 5-Diazo-2, 2-dimethyl-1, 3-dioxane-4, 6dione: Synthesis of Mono-and Bis-hydrazonyl NHC-Boranes. The Journal of organic chemistry, 83(15), 8775-8779.

61. Taniguchi, T. (2017). Recent advances in reactions of heteroatom-centered radicals. Synthesis, 49(16), 3511-3534.

62. Dai, W., McFadden, T. R., Curran, D. P., Früchtl, H. A., \& Walton, J. C. (2018). 5-Endo Cyclizations of NHC-Boraallyl Radicals Bearing Ester Substituents: Characterization of Derived 1, 2-Oxaborole Radicals and Boralactones. Journal of the American Chemical Society, 140(46), 15868-15875.

63. Dai, W., Curran, D. P., \& Walton, J. C. (2019). EPR and preparative studies of 5-endo cyclizations of radicals derived from alkenyl NHC-boranes 
bearing tert-butyl ester substituents. The Journal of organic chemistry, 84(4), 2102-2111.

64. Ren, S. C., Zhang, F. L., Qi, J., Huang, Y. S., Xu, A. Q., Yan, H. Y., \& Wang, Y. F. (2017). Radical borylation/cyclization cascade of 1, 6-enynes for the synthesis of boron-handled hetero-and carbocycles. Journal of the American Chemical Society, 139(17), 6050-6053.

65. Dai, W., Geib, S. J., \& Curran, D. P. (2019). RingOpening Reactions of NHC-Boriranes with In Situ Generated $\mathrm{HCl}$ : Synthesis of a New Class of NHC-Boralactones. Journal of the American Chemical Society, 141(8), 3623-3629.
66. Allen, T. H., \& Curran, D. P. (2016). Relative Reactivity of Stable Ligated Boranes and a Borohydride Salt in Rhodium (II)-Catalyzed Boron-Hydrogen Insertion Reactions. The Journal of Organic Chemistry, 81(5), 2094-2098.

67. Bernasconi, C. F., \& Pérez-Lorenzo, M. (2007). Does Aromaticity in a Reaction Product Increase or Decrease the Intrinsic Barrier? Kinetics of the Reversible Deprotonation of Benzofuran-3 (2 H)one and Benzothiophene-3 (2 H)-one. Journal of the American Chemical Society, 129(9), 27042712. 